\title{
Tourism experiences and the lower risk of mortality in the Chinese elderly: a national cohort study
}

\author{
Min Du', Liyuan Tao ${ }^{2}$, Min Liu and Jue Liư ${ }^{1,3,4^{*}}$
}

\begin{abstract}
Background: Cohort studies about the effects of tourism experiences on the risk of death among Chinese older adults are still lacking. We aimed to examine the association between tourism experiences and mortality in Chinese aged 65 or above.

Methods: We included 9520 participants aged 65 years or above from the Chinese Longitudinal Healthy Longevity Survey at baseline in 23 provinces in 2011. They were followed up in 2014 and 2018. Cox proportional hazards models were used to assess the association between tourism experiences and the risk of death.

Results: Among 9520 participants, $7.85 \%$ had at least one tourism experience outside of their local city/county during the past 2 years. During 35,994.26 person-years of follow-up, in total 4635 deaths were observed. The crude rate of death was greater in participants who had no tourism experience than in older travelers (incidence rate: 13.70 versus 5.24 per 100 person-years). Elderly travelers had a significantly lower risk for all-cause mortality (crude hazard ratio: 0.38, 95\% Cl: 0.33-0.44) compared with non-travelers. After adjustment for all covariates, the risk of allcause mortality was $27 \%$ lower among those with at least one tourism experience than among non-travelers (adjusted hazard ratio: $0.73,95 \% \mathrm{Cl}: 0.62-0.85$ ). Subgroup analysis showed that the associations between tourism and the decreased risk of mortality were stable.

Conclusions: Tourism decreases the risk of mortality in the Chinese elderly. Tourism should be considered as a modifiable lifestyle factor and an effective way to reduce mortality and promote longevity and healthy aging.
\end{abstract}

Keywords: Tourism, Mortality, Chinese, Older, Cohort

\section{Background}

Aging has become one of the great challenges worldwide [1-4]. According to the 2019 China Statistical Yearbook, there were 176 million people aged 65 or above, which accounted for $12.6 \%$ of the whole population in China [3]. Furthermore, it is estimated that there will be 400

\footnotetext{
* Correspondence: jueliu@bjmu.edu.cn

'Department of Epidemiology and Biostatistics, School of Public Health, Peking University, No.38, Xueyuan Road, Haidian District, Beijing 100191, China

${ }^{3}$ Institute for Global Health and Development, Peking University, Beijing 100871, China

Full list of author information is available at the end of the article
}

million Chinese citizens aged $\geq 65,150$ million of whom will be aged $\geq 80$, by 2050 [4]. The issue of aging implies broad global health implications, including mortality [5]. In the context of the disease burden from rapid population aging, behavior interventions such as reducing smoking [6], improving diet [7, 8], and appropriate physical activity have played an increasingly important role in shaping health among older adults.

Tourism is one type of physical activity. A previous meta-analysis has shown that physical activity can reduce the risk of death $[9,10]$, and sedentary behavior [11] can increase the risk of death in the general

(c) The Author(s). 2021 Open Access This article is licensed under a Creative Commons Attribution 4.0 International License, which permits use, sharing, adaptation, distribution and reproduction in any medium or format, as long as you give appropriate credit to the original author(s) and the source, provide a link to the Creative Commons licence, and indicate if changes were made. The images or other third party material in this article are included in the article's Creative Commons licence, unless indicated otherwise in a credit line to the material. If material is not included in the article's Creative Commons licence and your intended use is not permitted by statutory regulation or exceeds the permitted use, you will need to obtain permission directly from the copyright holder. To view a copy of this licence, visit http://creativecommons.org/licenses/by/4.0/. The Creative Commons Public Domain Dedication waiver (http://creativecommons.org/publicdomain/zero/1.0/) applies to the data made available in this article, unless otherwise stated in a credit line to the data. 
population. Previous studies in Brazil [3], Japan [12], Spain [13], and Korea [14] also reported that physical activity can reduce the risk of death among elderly, and absence of outdoor activities can increase the risk of death among older people [15]. However, studies reporting on the association between tourism and death among the general population or the elderly are scarce. However, it has been found that tourism is associated with the health situation of older people. One previous study reported that "forest bathing" (shinrin-yoku) trips have a positive effect on health among older patients with chronic obstructive pulmonary disease by reducing inflammation and stress levels [16]. Another crosssectional study found that tourism was positively associated with better self-rated health among Chinese people [17]. Chang et al. demonstrated that participation in domestic nature-based tourism served as a tonic to improve autonomic nervous system function [18]. Additionally, tourism has been reported to be beneficial for the psychological state, including wellbeing perception [19], perceived accessibility, and life satisfaction [20].

In fact, with the aging population, older people are more active in travel participation than previous generations [21,22]. Although there is evidence with respect to the association between tourism experiences and some health indices (including self-rated health, autonomic nervous system function, and psychological situation) among older people, it remains unclear whether tourism experiences have a direct effect on death after controlling for related confounding factors, including health status, exercise, and other leisure activities [17]. The association between tourism experiences and death among elderly is an emerging research field [21]. The Chinese Longitudinal Healthy Longevity Survey (CLHLS) was a nationally representative population-based survey that included 23 out of 31 provinces in China. This survey was utilized broadly in the aging research among Chinese elderly because of the complete information of elderly, such as demographics, lifestyle, and health status [23]. Therefore, in this study, we examined the association between tourism experiences and mortality in Chinese adults aged 65 years or above by using the data from the CLHLS, which can provide evidence on the links between tourism experiences and death among the elderly.

\section{Methods}

\section{Participants}

We used data from the CLHLS, a prospective nationwide cohort study that covered about $85 \%$ of the total population from a randomly selected half of the counties and cities in 23 of 31 provinces in China. A targeted randomsample design was adopted to ensure representativeness.
All of the centenarians of the sampled counties and cities agreed voluntarily to participate in the study. This study was established in 1998, with subsequent follow-up and recruitment of new participants in 2000, 2002, 2005, 2008, 2011, 2014, and 2018. This design serves well to provide information on the health status and quality of life among older people aged 65 or above [23].

The present analysis included data from the 2011 wave of the CLHLS (at baseline), which included the question "How many times did you have any tourism experience beyond your home county/city within the past two years?" The follow-up survey was conducted in 2014 and 2018. The CLHLS was approved by the Ethical Review Committee of Peking University (IRB00001052-13074). All of the participants signed informed consent at the time of participation. The research has been performed in accordance with the Declaration of Helsinki.

The 2011 wave included 9765 Chinese elderly individuals. We excluded 86 participants which were younger than 65 years old, and 159 participants for whom data on tourism experiences were missing. For the analysis of the association between tourism experience and allcause mortality, in total 9520 participants were included. Among these, 756 participants were lost to follow-up in 2014 and 1327 participants were lost to follow-up in 2018. Figure 1 shows the selection process of research participants in this study.

\section{Assessment of tourism experiences}

Participants' tourism experiences were obtained from the questionnaire answered at baseline by asking the participants the following question: "How many times did you have any tourism experience beyond your home county/city within the past two years?" Because only $4.5 \%$ of participants had two or more tourism experiences, according to the previous studies, participants were classified into two groups: those who had at least one tourism experience and those who had not [17].

\section{Covariates}

Trained investigators collected information, including basic demographic characteristics, lifestyle, health status, and socioeconomic status, using a standardized questionnaire. All of the surveys were face-to-face interviews conducted at the participants' homes. If participants were illiterate, investigators helped them to complete the questionnaire. Details of the study design have been described elsewhere, and the quality of the data was reported to be generally good [24].

Basic demographic characteristics included age $(<85 / \geq$ 85), sex (male/female), education (no school/1 year or more), residence (urban/rural), marital status (unmar$\mathrm{ried} / \mathrm{married} /$ divorced or widowed), and living pattern 


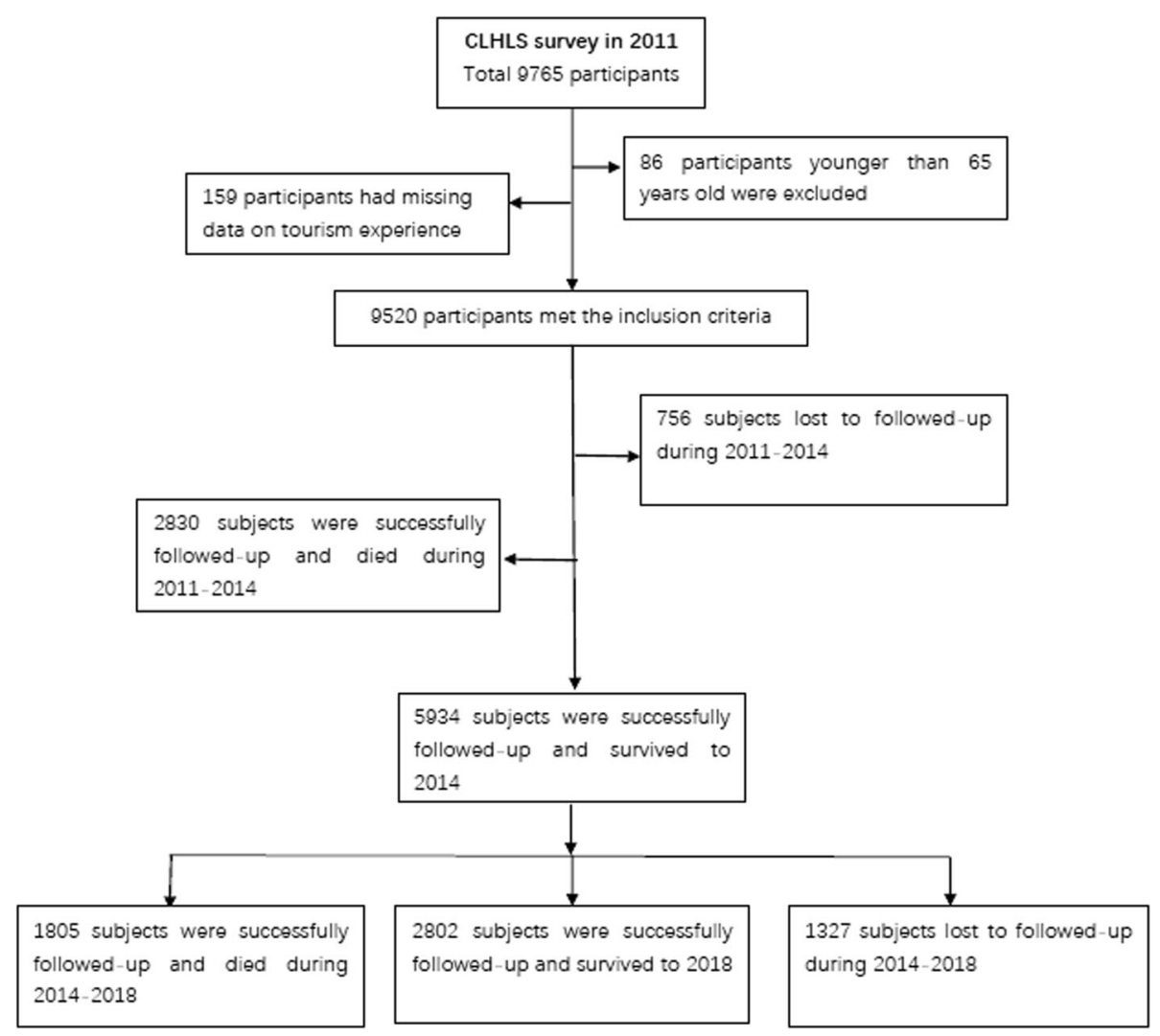

Fig. 1 Flowchart of the inclusion of participants

(living with family members/living alone or in an institution).

Lifestyle characteristics included smoking status (nonsmoker/smoker), drinking status (non-drinker/drinker), regular exercise (yes/no), leisure activities, and dietary diversity score (DDS, good/poor). According to a study by $\mathrm{Gu}$ et al. [17], the frequency of involvement in leisure activities and doing regular exercise were considered competing activities that may confound the effect of tourism participation on health, so we included regular exercise and leisure activities. Leisure activities were measured by asking about the frequencies of eight dummy leisure activities, including housework, gardening, outdoor activities, raising poultry or pets, reading, playing cards/Mahjong, listening to the radio/watching television, and participating in organized social activities. The answer of each leisure activity was categorized as 0 (never) or 1 (sometimes or almost). We summed the scores (ranging from 0 to 8 ) to calculate the frequency of leisure activities [17]. The DDS was categorized according to the recommendations by the Food and Agriculture Organization of the United Nations and previous research [25].

Health status was measured on the basis of body mass index (BMI) (underweight/normal/overweight/obese), depression (yes/no), history of chronic diseases (hypertension, diabetes, heart diseases, and stroke; yes/no/unknown), history of cancer (yes/no/unknown), history of arthritis (yes/no/unknown), cognitive impairment (yes/ no), activities of daily living (ADL in disability; yes/no), and toothache or pain in the jaw joint more than once during the past 6 months (yes/no). In accordance with the World Health Organization cutoff values, BMI was categorized as underweight $\left(<18.5 \mathrm{~kg} / \mathrm{m}^{2}\right)$, normal $\left(18.5-24.9 \mathrm{~kg} / \mathrm{m}^{2}\right)$, overweight $\left(25-29.9 \mathrm{~kg} / \mathrm{m}^{2}\right)$, or obese $\left(\geq 30 \mathrm{~kg} / \mathrm{m}^{2}\right)$. Depression was assessed by the following question: "Have you felt sad, blue, or depressed for two weeks or more in the last 12 months?" Cognitive function was measured by using the Chinese version of the Mini-Mental State Examination (MMSE), which consists of 11 questions covering orientation, registration, attention, calculation, recall, and language abilities [26]. Several items of the MMSE were adapted to the Chinese cultural context with good validity and reliability [27]. The total MMSE scores ranged from 0 to 30; CLHLS participants who scored less than 18 in the Chinese version of the MMSE were classified as having cognitive impairment, whereas participants with a score of 18 or higher were classified as having no cognitive impairment $[28,29]$. ADL refers to basic personal care tasks of 
everyday life. In this study, ADL in disability was defined as self-reported difficulty with any of the following ADL items [30]: dressing, eating, bathing, continence, toileting, cleaning, and indoor movement.

Socioeconomic status (SES) was assessed by two indices, including childhood SES and adult SES. We evaluated childhood SES by the following question: "Did you often go to bed hungry as a child?" (yes/no/unknown). Adult SES was evaluated by the following question: "How do you rate your economic status compared with other local people?" Participants who answered "very rich" or "rich" were classified as good adult SES, and participants who answered "so-so," "poor," or "very poor" were classified as poor adult SES.

\section{Data analysis}

Baseline characteristics of the study population are presented as the mean \pm standard deviation (SD) for continuous variables or as percentages for categorical variables. Time to death (event $=1$ ) was defined as the period between the baseline survey and death. This study included two follow-up surveys, in 2014 and 2018. For participants who died before the 2014 follow-up, family members were contacted to investigate the date of death based on the medical records. For participants who died between the 2014 and 2018 follow-ups, the date of death was investigated in the same way. Censoring (event $=0$ ) was performed for surviving participants or those lost to follow-up in 2014. The censoring time was calculated from baseline to the survey of 2014/2018, which was updated. Survival was estimated by the Kaplan-Meier method (Fig. S1), and the difference in survival was evaluated with a stratified log-rank test $(P<$ 0.0001). Cox proportional hazards models were used to assess the association of tourism experiences with allcause mortality. The proportional hazard assumption was evaluated by tests based on Schoenfeld residuals [31], which showed no violation of this assumption in our analyses $(P=0.17)$. We performed a sensitivity analysis by fitting different models to examine the robustness of the estimation. Model 1 was a univariate model without adjustment for any confounders. We adjusted for basic demographic characteristics, including age, sex, education, residence, marital status, and living pattern, in model 2. We adjusted for all of the covariates in model 3 by adding smoking status, drinking status, regular exercise, leisure activities, dietary diversity, BMI, depression, cognitive impairment, ADL in disability, selfreported chronic diseases including hypertension, diabetes, heart diseases, and stroke, history of cancer, history of arthritis, toothache or pain in the jaw joint more than once during the past 6 months, childhood SES, and adult SES. The missing data of every covariates used in this study was all less than 5\%. Therefore, we did not further treat missing values (such as multiple imputation). In the models, if there was missing data, the cases were not included in the analysis. We calculated crude incidence rates (IRs) (per 100 person-years) of death across categories of tourism experiences. Our results are presented as pooled hazard ratios (HRs) or $\beta$-values with 95\% confidence intervals (CIs).

Additionally, a stratified analysis was performed by age, sex, education, residence, marital status, living pattern, smoking status, drinking status, regular exercise, leisure activities, dietary diversity, BMI, depression, cognitive impairment, ADL in disability, self-reported chronic diseases, history of cancer, history of arthritis, and toothache or pain in the jaw joint more than once during the past 6 months, and the significance of the interaction was tested by including a two-way interaction term in the final model.

In order to test the robustness of the results, we did additional analysis as followings: (1) There were 756 participants who never responded to the follow-up, so we compared the characteristics between 756 participants and the other 8764 participants, which showed that differences of most characteristics were insignificant (Table S1). (2) Cox models were performed for the 8764 participants who responded at least once to follow-up (in 2014 or 2018, excluding the 756 participants who never responded) (Table S2). (3) For the 9520 participants at baseline, Cox model A, which was adjusted for all of the covariates except regular exercise and leisure activities, and model B, which was adjusted for all of the covariates after multiple imputation of missing values, were generated (Table S3).

$P$-values below 0.05 were considered to indicate statistical significance. All of the analyses were performed with SPSS 26.0 and Stata 16.0.

\section{Results}

Basic characteristics of the participants

Characteristics of the 9520 participants at baseline are shown in Table 1 . The mean age was $85.95( \pm 11.21)$ years, and $44.78 \%$ of participants were men. Overall, $7.85 \%$ (747/9520) of participants had at least one tourism experience outside of their local city/county during the previous 2 years at baseline.

Participants who were male, aged $<85$ years, literate, married, citizen, smoker, drinker, overweight, and not depressed, participants who performed more leisure activities or did regular exercise, and participants with good dietary diversity, chronic disease (including hypertension, diabetes, and heart diseases), cancer, arthritis, toothache or pain in the jaw joint more than once during the past 6 months, and good childhood SES and good adult SES and without cognitive impairment and 
Table 1 Characteristics of the study participants according to tourist experiences at baseline

\begin{tabular}{|c|c|c|c|c|c|}
\hline \multirow[t]{3}{*}{ Characteristics } & \multirow[t]{3}{*}{$\mathbf{N}$} & \multicolumn{2}{|l|}{ Tourism experiences } & \multirow[t]{3}{*}{$t / x^{2}$} & \multirow[t]{3}{*}{$P$} \\
\hline & & \multicolumn{2}{|l|}{ Mean \pm SD or $n(\%)$} & & \\
\hline & & $\begin{array}{l}0 \text { times within the past } \\
\text { two years }\end{array}$ & $\begin{array}{l}\geq 1 \text { times within the past } \\
\text { two years }\end{array}$ & & \\
\hline Total & & $8773(92.15)$ & $747(7.85)$ & & \\
\hline \multicolumn{6}{|l|}{ Basic demographic characteristics } \\
\hline Age (years) & & & & 248.867 & $<0.0001$ \\
\hline$<85$ & 4417 & $3864(87.48)$ & $553(12.52)$ & & \\
\hline$\geq 85$ & 5103 & $4909(96.20)$ & $194(3.80)$ & & \\
\hline Sex & & & & 25.202 & $<0.0001$ \\
\hline Male & 4263 & $3863(90.62)$ & $400(9.38)$ & & \\
\hline Female & 5257 & $4910(93.40)$ & $347(6.60)$ & & \\
\hline Education & & & & 209.587 & $<0.0001$ \\
\hline No school & 5535 & $5286(95.50)$ & $249(4.50)$ & & \\
\hline 1 year or more & 3944 & $3446(87.37)$ & $498(12.63)$ & & \\
\hline Residence & & & & 93.101 & $<0.0001$ \\
\hline Urban & 4544 & $4061(89.37)$ & $483(10.63)$ & & \\
\hline Rural & 4976 & $4712(94.69)$ & $264(5.31)$ & & \\
\hline Marital status & & & & 135.646 & $<0.0001$ \\
\hline Unmarried & 98 & $93(94.90)$ & $5(5.10)$ & & \\
\hline Married & 3586 & $3157(88.04)$ & $429(11.96)$ & & \\
\hline Divorced or widowed & 5806 & $5496(94.66)$ & $310(5.34)$ & & \\
\hline Living pattern & & & & 1.291 & 0.256 \\
\hline Living with family members & 7647 & $7033(91.97)$ & $614(8.03)$ & & \\
\hline Living alone/in an institution & 1812 & $1681(92.77)$ & $131(7.23)$ & & \\
\hline \multicolumn{6}{|l|}{ Lifestyle characteristics } \\
\hline Smoking status & & & & 21.957 & $<0.0001$ \\
\hline Non-smoker & 6254 & $5819(93.04)$ & $435(6.96)$ & & \\
\hline Smoker & 3218 & $2906(90.30)$ & $312(9.70)$ & & \\
\hline Drinking status & & & & 23.601 & $<0.0001$ \\
\hline Non-drinker & 6467 & $6018(93.06)$ & $449(6.94)$ & & \\
\hline Drinker & 2956 & $2665(90.16)$ & $291(9.84)$ & & \\
\hline Regular exercise & & & & 205.746 & $<0.0001$ \\
\hline Yes & 4302 & $3778(87.82)$ & $524(12.18)$ & & \\
\hline No & 5101 & $4887(95.80)$ & $214(4.20)$ & & \\
\hline Leisure activities & 9492 & $2.62( \pm 1.87)$ & $4.40( \pm 1.77)$ & -26.274 & $<0.0001$ \\
\hline Dietary diversity score & & & & 177.506 & $<0.0001$ \\
\hline Poor & 4868 & $4661(95.75)$ & $207(4.25)$ & & \\
\hline Good & 4648 & $4109(88.40)$ & $539(11.60)$ & & \\
\hline \multicolumn{6}{|l|}{ Health status } \\
\hline Body mass index $\left(\mathrm{kg} / \mathrm{m}^{2}\right)$ & & & & 70.359 & $<0.0001$ \\
\hline Underweight (<18.5) & 2379 & $2268(95.33)$ & $111(4.67)$ & & \\
\hline Normal (18.5-24.9) & 5398 & $4933(91.39)$ & $465(8.61)$ & & \\
\hline Overweight (25-29.9) & 1062 & $931(87.66)$ & $131(12.34)$ & & \\
\hline Obese $(\geq 30)$ & 288 & $254(88.19)$ & $34(11.81)$ & & \\
\hline Depression & & & & 89.841 & $<0.0001$ \\
\hline
\end{tabular}


Table 1 Characteristics of the study participants according to tourist experiences at baseline (Continued)

\begin{tabular}{|c|c|c|c|c|c|}
\hline \multirow[t]{3}{*}{ Characteristics } & \multirow[t]{3}{*}{$\mathbf{N}$} & \multicolumn{2}{|l|}{ Tourism experiences } & \multirow[t]{3}{*}{$t / x^{2}$} & \multirow[t]{3}{*}{$P$} \\
\hline & & \multicolumn{2}{|l|}{ Mean \pm SD or $n(\%)$} & & \\
\hline & & $\begin{array}{l}0 \text { times within the past } \\
\text { two years }\end{array}$ & $\begin{array}{l}\geq 1 \text { times within the past } \\
\text { two years }\end{array}$ & & \\
\hline Yes & 1200 & $1102(91.83)$ & $98(8.17)$ & & \\
\hline No & 6725 & $6109(90.84)$ & $616(9.16)$ & & \\
\hline Unknown & 1595 & $1562(97.93)$ & $33(2.07)$ & & \\
\hline Hypertension & & & & 15.416 & $<0.0001$ \\
\hline Yes & 2695 & $2444(90.69)$ & $251(9.31)$ & & \\
\hline No & 6414 & $5937(92.56)$ & $477(7.44)$ & & \\
\hline Unknown & 411 & 392 (95.38) & $19(4.62)$ & & \\
\hline Diabetes & & & & 34.445 & $<0.0001$ \\
\hline Yes & 393 & 333 (84.73) & $60(15.27)$ & & \\
\hline No & 8629 & 7969 (92.35) & $660(7.65)$ & & \\
\hline Unknown & 498 & $471(94.58)$ & $27(5.42)$ & & \\
\hline Heart diseases & & & & 15.729 & $<0.0001$ \\
\hline Yes & 1155 & $1031(89.26)$ & $124(10.74)$ & & \\
\hline No & 7892 & $7300(92.50)$ & $592(7.50)$ & & \\
\hline Unknown & 473 & $442(93.45)$ & $31(6.55)$ & & \\
\hline Stroke & & & & 2.1 & 0.35 \\
\hline Yes & 783 & $732(93.49)$ & $51(6.51)$ & & \\
\hline No & 8301 & $7640(92.04)$ & $661(7.96)$ & & \\
\hline Unknown & 436 & $401(91.97)$ & $35(8.03)$ & & \\
\hline Cancer & & & & 9.012 & 0.011 \\
\hline Yes & 81 & $68(83.95)$ & $13(16.05)$ & & \\
\hline No & 8896 & 8197(92.14) & $699(7.86)$ & & \\
\hline Unknown & 543 & $508(93.55)$ & $35(6.45)$ & & \\
\hline Arthritis & & & & 6.986 & 0.030 \\
\hline Yes & 1319 & $1192(90.37)$ & $127(9.63)$ & & \\
\hline No & 7781 & $7190(92.40)$ & $591(7.60)$ & & \\
\hline Unknown & 420 & 391 (93.10) & $29(6.90)$ & & \\
\hline Cognitive impairment & & & & 154.251 & $<0.0001$ \\
\hline Yes & 2349 & $2305(98.13)$ & $44(1.87)$ & & \\
\hline No & 7160 & $6457(90.18)$ & $703(9.82)$ & & \\
\hline $\mathrm{ADL}$ in disability & & & & 103.425 & $<0.0001$ \\
\hline Yes & 2473 & $2395(96.85)$ & $78(3.15)$ & & \\
\hline No & 6825 & $6171(90.42)$ & $654(9.58)$ & & \\
\hline $\begin{array}{l}\text { Toothache or pain in the jaw joint more than once during } \\
\text { the past } 6 \text { months }\end{array}$ & & & & 40.357 & $<0.0001$ \\
\hline Yes & 1654 & $1461(88.33)$ & $193(11.67)$ & & \\
\hline No & 7596 & $7062(92.97)$ & $534(7.03)$ & & \\
\hline Socioeconomic status & & & & & \\
\hline Childhood SES & & & & 33.618 & $<0.0001$ \\
\hline Yes & 6315 & $5862(92.83)$ & $453(7.17)$ & & \\
\hline No & 2024 & $1804(89.13)$ & $220(10.87)$ & & \\
\hline Unknown & 1181 & $1107(93.73)$ & $74(6.27)$ & & \\
\hline
\end{tabular}


Table 1 Characteristics of the study participants according to tourist experiences at baseline (Continued)

\begin{tabular}{|c|c|c|c|c|c|}
\hline \multirow[t]{3}{*}{ Characteristics } & \multirow[t]{3}{*}{$\mathrm{N}$} & \multicolumn{2}{|l|}{ Tourism experiences } & \multirow[t]{3}{*}{$t / x^{2}$} & \multirow[t]{3}{*}{$P$} \\
\hline & & \multicolumn{2}{|l|}{ Mean \pm SD or $n(\%)$} & & \\
\hline & & $\begin{array}{l}0 \text { times within the past } \\
\text { two years }\end{array}$ & $\begin{array}{l}\geq 1 \text { times within the past } \\
\text { two years }\end{array}$ & & \\
\hline Adult SES & & & & 94.262 & $<0.0001$ \\
\hline Good & 1619 & $1395(86.16)$ & $224(13.84)$ & & \\
\hline Poor & 7800 & 7279 (93.32) & $521(6.68)$ & & \\
\hline
\end{tabular}

Notes: Missing data: Basic demographic characteristics: education 41 (0.43\%), marital status 30 (0.32\%), and living pattern 61 (0.64\%); Lifestyle characteristics: smoking status $48(0.50 \%)$, drinking status $97(1.02 \%)$, regular exercise $117(1.23 \%)$, leisure activities $28(0.29 \%)$, DDS 4 (0.04\%); health status: BMI 393 (4.13\%), cognitive impairment $11(0.12 \%), A D L$ in disability $222(2.33 \%)$, toothache or pain in the jaw joint more than once during the past 6 months 270 (2.84\%); socioeconomic status: adult SES $101(1.06 \%)$

disability were more likely to have had a tourism experience during the past 2 years $(P<0.05$, Table 1$)$. However, tourism experiences were not associated with living patterns and history of stroke $(P>0.05)$.

\section{Association of tourism experiences with all-cause mortality}

During 35,994.26 person-years of follow-up (median survival time: 2.88 years overall; 2.86 years for the group with zero tourism experiences within the past 2 years; 5.34 years for the group with $\geq 1$ tourism experience within the past 2 years), a total of 4635 deaths were observed, including 4452 participants who had no tourism experience and 183 older travelers (IR: 13.70 versus 5.24 per 100 person-years). Overall, the crude rate of death was higher in participants who had tourism experience than in older travelers (Table 2). In the unadjusted analysis, older travelers had a lower risk for all-cause mortality (crude HR [cHR]: 0.38, 95\% CI: 0.33-0.44). After adjusting for basic demographic characteristics including age, sex, education, residence, marital status, and living pattern, the association remained significant (adjusted HR [aHR]: 0.57, 95\% CI: 0.49-0.66). In multivariable models, after adjustment for all covariates, compared to the older people who had no tourism experience, the risk of all-cause mortality was $27 \%$ lower among older travelers (aHR: 0.73, 95\% CI: 0.62-0.85) (Table 2).

\section{Subgroup analysis}

In the subgroup analysis, the associations between tourism and the risk of mortality were stable. We stratified the analysis by age, sex, education, residence, marital status, living pattern, smoking status, drinking status, regular exercise, leisure activities, dietary diversity, BMI, depression, cognitive impairment, ADL in disability, selfreported chronic diseases, history of cancer, history of arthritis, and toothache or pain in the jaw joint more than once during the past 6 months in the multivariable model. Significant group differences in smoking status were found on the basis of the association of tourism experiences with mortality in the multivariable-adjusted model ( $P$-values for the interaction $<0.05$ ). The risk of mortality was lower among participants who never smoked (aHR: 0.64, 95\% CI: 0.51-0.80). No interaction was observed within the other groups (Table 3 ).

\section{Discussion}

To our knowledge, this is the first nationwide cohort study that examined the association of tourism experiences with all-cause deaths among Chinese older people aged $\geq 65$ years. In this prospective cohort study, we

Table 2 Association of tourism experiences with mortality in the univariate and multivariable models

\begin{tabular}{|c|c|c|c|c|c|c|c|}
\hline \multirow[t]{2}{*}{ Tourist experience } & \multirow[b]{2}{*}{$\begin{array}{l}\text { Number } \\
\text { of events/ } \\
\text { incidence } \\
\text { rate (per } \\
100 \\
\text { person- } \\
\text { years) }\end{array}$} & \multicolumn{2}{|l|}{ Model 1} & \multicolumn{2}{|l|}{ Model 2} & \multicolumn{2}{|l|}{ Model 3} \\
\hline & & cHR $(95 \% \mathrm{Cl})$ & $P$ & aHR $(95 \% \mathrm{Cl})$ & $P$ & aHR $(95 \% \mathrm{Cl})$ & $P$ \\
\hline 0 times within the past 2 years & $4452 / 13.70$ & 1 (reference) & & 1 (reference) & & 1 (reference) & \\
\hline$\geq 1$ times within the past 2 years & $183 / 5.24$ & $0.38(0.33-0.44)$ & $<0.0001$ & $0.57(0.49-0.66)$ & $<0.0001$ & $0.73(0.62-0.85)$ & $<0.0001$ \\
\hline
\end{tabular}

Notes: Model 1 is a univariate model. In model 2, we adjusted for basic demographic characteristics, including age, sex, education, residence, marital status, and living pattern. In model 3, we adjusted for all covariates by adding smoking status, drinking status, regular exercise, leisure activities, dietary diversity, BMl, depression, cognitive impairment, ADL in disability, history of chronic disease (hypertension, diabetes, heart diseases, and stroke), history of cancer, history of arthritis, toothache or pain in the jaw joint more than once during the past 6 months, childhood SES, and adult SES. cHR, crude hazard ratio; aHR, adjusted hazard ratio 
Table 3 Subgroup analysis for the association of tourism experiences with mortality

\begin{tabular}{|c|c|}
\hline \multirow[t]{2}{*}{ Subgroup } & \multirow{2}{*}{$\frac{\geq 1 \text { times with }}{\text { Adjusted HR }}$} \\
\hline & \\
\hline All & $0.73(0.62-0.85)$ \\
\hline \multicolumn{2}{|l|}{ Basic demographic characteristics } \\
\hline \multicolumn{2}{|l|}{ Age (years) } \\
\hline$<85$ & $0.80(0.64-1.01)$ \\
\hline$\geq 85$ & $0.70(0.56-0.87)$ \\
\hline \multicolumn{2}{|l|}{ Sex } \\
\hline Male & $0.75(0.61-0.93)$ \\
\hline Female & $0.69(0.53-0.88)$ \\
\hline \multicolumn{2}{|l|}{ Education } \\
\hline No school & $0.68(0.52-0.87)$ \\
\hline 1 year or more & $0.76(0.62-0.94)$ \\
\hline \multicolumn{2}{|l|}{ Residence } \\
\hline Urban & $0.66(0.54-0.81)$ \\
\hline Rural & $0.85(0.65-1.09)$ \\
\hline \multicolumn{2}{|l|}{ Marital status } \\
\hline Unmarried & $0.47(0.04-6.34)$ \\
\hline Married & $0.71(0.55-0.92)$ \\
\hline Divorced or widowed & $0.74(0.60-0.91)$ \\
\hline \multicolumn{2}{|l|}{ Living pattern } \\
\hline Living with family members & $0.76(0.64-0.90)$ \\
\hline Living alone/in an institution & $0.59(0.38-0.89)$ \\
\hline
\end{tabular}

\section{Lifestyle characteristics}

$\begin{array}{ll}\text { Smoking status } & \\ \text { Non-smoker } & 0.64(0.51-0.80) \\ \text { Smoker } & 0.82(0.65-1.04) \\ \text { Drinking status } & \\ \text { Non-drinker } & 0.79(0.64-0.97) \\ \text { Drinker } & 0.66(0.51-0.86) \\ \text { Regular exercise } & \\ \text { Yes } & 0.73(0.60-0.89) \\ \text { No } & 0.70(0.53-0.94) \\ \text { Leisure activities (median) } & \\ \text { 0-3 } & 0.73(0.58-0.92) \\ \text { 4-8 } & 0.70(0.56-0.88) \\ \text { Dietary diversity score } & \\ \text { Poor } & 0.75(0.57-0.99) \\ \text { Good } & 0.73(0.60-0.88) \\ \text { Health status } & \\ \text { Body mass index }\left(\mathrm{kg} / \mathrm{m}^{2}\right) & \\ \text { Underweight }(<18.5) & 0.65(0.70-1.77) \\ \text { Normal (18.5-24.9) } & \\ \text { Overweight }(25-29.9) & 0.23-1.87) \\ \text { Obese }(\geq 30) & 0.69(0.52-0.99) \\ \end{array}$


Table 3 Subgroup analysis for the association of tourism experiences with mortality (Continued)

\begin{tabular}{|c|c|c|}
\hline \multirow[t]{2}{*}{ Subgroup } & \multicolumn{2}{|c|}{$\geq 1$ times within the past 2 years } \\
\hline & Adjusted HR (95\% CI) & $P$ for interaction \\
\hline Depression & & 0.442 \\
\hline Yes & $0.62(0.40-0.96)$ & \\
\hline No & $0.75(0.63-0.90)$ & \\
\hline Unknown & $0.59(0.29-1.20)$ & \\
\hline Hypertension & & 0.633 \\
\hline Yes & $0.78(0.58-1.05)$ & \\
\hline No & $0.72(0.60-0.88)$ & \\
\hline Unknown & $0.41(0.14-1.23)$ & \\
\hline Diabetes & & 0.666 \\
\hline Yes & $0.80(0.45-1.42)$ & \\
\hline No & $0.72(0.60-0.85)$ & \\
\hline Unknown & $0.60(0.24-1.53)$ & \\
\hline Heart diseases & & 0.753 \\
\hline Yes & $0.78(0.51-1.19)$ & \\
\hline No & $0.74(0.62-0.88)$ & \\
\hline Unknown & $0.51(0.20-1.28)$ & \\
\hline Stroke & & 0.223 \\
\hline Yes & $1.64(0.97-2.76)$ & \\
\hline No & $0.68(0.57-0.81)$ & \\
\hline Unknown & $0.61(0.29-1.31)$ & \\
\hline Cancer & & 0.724 \\
\hline Yes & $0.05(0.01-0.57)$ & \\
\hline No & $0.72(0.61-0.85)$ & \\
\hline Unknown & $0.72(0.34-1.53)$ & \\
\hline Arthritis & & 0.670 \\
\hline Yes & $0.89(0.60-1.33)$ & \\
\hline No & $0.70(0.58-0.84)$ & \\
\hline Unknown & $0.79(0.34-1.81)$ & \\
\hline Cognitive impairment & & 0.448 \\
\hline Yes & $0.87(0.57-1.32)$ & \\
\hline No & $0.72(0.60-0.85)$ & \\
\hline$A D L$ in disability & & 0.239 \\
\hline Yes & $0.84(0.60-1.19)$ & \\
\hline No & $0.71(0.59-0.85)$ & \\
\hline Toothache or pain in the jaw joint more than once during the past 6 months & & 0.674 \\
\hline Yes & $0.58(0.41-0.84)$ & \\
\hline No & $0.77(0.65-0.93)$ & \\
\hline \multicolumn{3}{|l|}{ Socioeconomic status } \\
\hline Childhood SES & & 0.369 \\
\hline Yes & $0.74(0.61-0.91)$ & \\
\hline No & $0.76(0.56-1.04)$ & \\
\hline Unknown & $0.47(0.24-0.94)$ & \\
\hline
\end{tabular}

$\geq 1$ times within the past 2 years

Adjusted HR (95\% Cl)

$0.62(0.40-0.96)$

$0.75(0.63-0.90)$

$0.59(0.29-1.20)$

$0.78(0.58-1.05)$

$0.72(0.60-0.88)$

$0.41(0.14-1.23)$

$0.80(0.45-1.42)$

$0.72(0.60-0.85)$

$0.60(0.24-1.53)$

$0.78(0.51-1.19)$

$0.74(0.62-0.88)$

$0.51(0.20-1.28)$

$1.64(0.97-2.76)$

$61(0.29-1.31)$

$0.05(0.01-0.57)$

$.72(0.34-1.53)$

$0.89(0.60-1.33)$

$0.47(0.24-0.94)$ 
Table 3 Subgroup analysis for the association of tourism experiences with mortality (Continued)

\begin{tabular}{cl}
\hline Subgroup & $\geq \mathbf{1}$ times within the past $\mathbf{2}$ years \\
\cline { 2 - 2 } & Adjusted HR (95\% Cl) $\quad 0.86(0.64-1.15)$ \\
Good & $0.68(0.56-0.83)$
\end{tabular}

Notes: We adjusted for all covariates, including age, sex, education, residence, marital status, living pattern, smoking status, drinking status, regular exercise, leisure activities, dietary diversity, BMI, depression, cognitive impairment, ADL in disability, history of chronic disease (hypertension, diabetes, heart diseases, and stroke), history of cancer, history of arthritis, toothache or pain in the jaw joint more than once during the past 6 months, childhood SES, and adult SES. cHR, crude hazard ratio; aHR, adjusted hazard ratio

found that elderly people who had at least one tourism experience within the past 2 years had a significantly decreased risk of all-cause death, after adjustment for age, sex, education, residence, marital status, living pattern, smoking status, drinking status, regular exercise, leisure activities, dietary diversity, BMI, depression, cognitive impairment, ADL in disability, history of chronic disease (hypertension, diabetes, heart diseases, and stroke), history of cancer, history of arthritis, toothache or pain in the jaw joint more than once during the past 6 months, childhood SES, and adult SES.

Although there was no study that explored the relationship between tourism experiences and mortality among elderly, our findings still echoed some findings from the limited existing research regarding the effect of tourism on physiology and health among older people. $\mathrm{Gu}$ et al. reported that after controlling for confounders such as demographic variables, SES, and health behaviors, individuals who had one or more tourism experiences in the past 2 years were $20 \%$ less likely to report poor health (odds ratio: 0.80, $P<0.01$ ) among Chinese older people in a panel study [17]. Chang et al. found that participation in domestic nature-based tourism served as a tonic to improve autonomic nervous system function $(\beta=0.20, P<0.01)[18]$. Considering tourism is likely to be a type of outdoor activity, studies which explored the effects of participation in similar activities on the risk of death showed similar results. Sufficient physical activity was reported to be a protective factor for death among elderly [3, 12-14], and insufficient activity can increase the risk of death among older people [15]. Moreover, it is assumed that people with more tourism experiences may have had more exposure to nature. A meta-analysis showed that exposure to greenery is associated with a reduced risk of all-cause mortality (HR: $0.99,95 \%$ CI: $0.97-1.00$ ) [32]. Jia et al. found that "forest bathing" trips have beneficial effects on chronic obstructive pulmonary disease in older patients by decreasing the serum levels of interferon- $\gamma$, interleukin-6, and interleukin-8 [16]. Previous limited studies also explored the association of tourism with the psychological state, including perceived wellbeing
[19], perceived accessibility, and life satisfaction [20]. Our study was conducted in a large area including 23 research locations in 23 provinces in mainland China, and we corrected for basic demographic characteristics, lifestyle, health-related factors, and socioeconomic status, which could be related to tourism or mortality. We found that after adjustment for all of the covariates, compared to elderly without travel experience, older travelers had a $27 \%$ lower risk of death. That is, given the biopsychosocial impact and the comfortable options for older people, tourism appears particularly well suited for older people to reduce mortality. We found that older travelers had a lower risk of death than the entire elderly population, irrespective of regular exercise and leisure activities. This finding may suggest that tourism experience has a strong protective effect on mortality among elderly, independent from exercise and leisure activities.

The specific potential biological mechanism between tourism and all-cause mortality may be related with the effect of physical activity on the human body. Physical activity may stimulate anti-tumor and antioxidant defense systems [14]. In addition, physical activity has been reported to be associated with lower mortality among older people with low serum lipid profiles [33], high insulin sensitivity [34], and reduced muscle inflammation [35]. Of note, biological mechanisms linking tourism and all-cause mortality need to be further explored and verified.

In the present study, $7.85 \%$ of participants had one or more tourism experiences during the past 2 years, which was similar to previous studies [17]. Besides, we found that a wide array of factors distinguishes tourists from non-tourists among the older Chinese population, including demographic characteristics (such as sex, age, and education), lifestyle (such as smoking, drinking, and leisure activities), socioeconomic status (childhood SES and adult SES), and health status (such as BMI, chronic disease history, and depression). Health conditions arose as the most frequently indicated barrier for participation in tourism among older Polish people [36]. We found that participants with depression and cognitive 
impairment were less likely to travel, suggesting that mental health may also be a barrier for physical activity among older people.

\section{Strengths and limitations}

A major strength of this national cohort study is our estimation of the impact of tourism experience on all-cause mortality among older people in China, the first such study of its kind. However, we wish to highlight several limitations. First, we only included participants from mainland China, so the results may not be generalizable to populations form other nations, because different habits and customs exist in different countries. Second, the specific tourism type, such as nature/city trips, time spent traveling, and the transportation mode used, were not collected, so we could not explore deeply about the effect of trips on mortality deeply. Third, SES was obtained through relatively simple questions and need to be improved by multiple indexes or questions in the future. Fourth, although we controlled health-related factors, including chronic disease history, cognition, history of cancer, and arthritis, as much as possible, it is impossible to completely control all health-related factors, which may have had a confounding effect on our results. Finally, the specific cause of death was not recorded in the CLHLS study, so we could not explore the association of tourism with specific causes of death.

\section{Conclusions}

In this nationwide prospective cohort study, tourism experience was associated with reduced mortality in the Chinese elderly population. Our findings suggested that tourism should be considered as a modifiable lifestyle factor for the older people to reduce mortality. Additionally, tourism is an effective way to promote longevity and healthy aging.

\section{Abbreviations}

ADL: Activities of daily living; BMI: Body mass index; CLHLS: Chinese Longitudinal Healthy Longevity Survey; DDS: Dietary diversity score; HR: Hazard ratios; IR : Incidence rates; MMSE: Mini-Mental State Examination; SDs: Standard deviations

\section{Supplementary Information}

The online version contains supplementary material available at https://doi. org/10.1186/s12889-021-11099-8

Additional file 1: Figure S1. Overall Survival among all 9750

Participants. Table S1. Comparison of characteristics between 756 participants who never responded to the follow-up and others among all 9520 participants at baseline. Table S2. Association of tourism experiences with mortality in the univariate and multivariable models among 8764 participants who responded at least once to the follow-up 2014 or 2018. Table S3. Association of tourism experiences with mortality in the multivariable model.

\section{Acknowledgments}

We thank the members of the CLHLS study group for data collection and all the participants

\section{Authors' contributions}

All the authors have made substantial contributions to the conception, design of the work; or the acquisition, analysis, or interpretation of data for the work. They have participated in drafting the manuscript and approval of the version to be published. Conceptualization: JL. Formal analysis: MD. Writing - original draft: MD. Writing - review \& editing: LT, ML, JL. Funding acquisition: JL. Supervision: JL.

\section{Funding}

This work was supported by the National Key Research and Development Project of China (2019YFC1710301; 2020YFC0846300).

\section{Availability of data and materials}

Data are from the Chinese Longitudinal Healthy Longevity Survey 2011-2018 which is a public, open access repository (https://opendata.pku.edu.cn).

\section{Declarations}

Ethics approval and consent to participate

The CLHLS was approved by the Ethical Review Committee of Peking University (IRB00001052-13074). All participants signed the informed consent at the time of participation. The research has been performed in accordance with the Declaration of Helsinki.

\section{Consent for publication}

Not applicable.

\section{Competing interests}

All authors report no conflict of interest.

\section{Author details}

${ }^{1}$ Department of Epidemiology and Biostatistics, School of Public Health, Peking University, No.38, Xueyuan Road, Haidian District, Beijing 100191, China. ${ }^{2}$ Research Center of Clinical Epidemiology, Peking University Third Hospital, No.49 Huayuan North Road, Haidian District, Beijing 100083, China. ${ }^{3}$ Institute for Global Health and Development, Peking University, Beijing 100871, China. ${ }^{4}$ Key Laboratory of Reproductive Health, National Health Commission of the People's Republic of China, Beijing 100083, China.

Received: 17 January 2021 Accepted: 18 May 2021

Published online: 27 May 2021

\section{References}

1. Chang AY, Skirbekk VF, Tyrovolas S, Kassebaum NJ, Dieleman JL. Measuring population ageing: an analysis of the global burden of disease study 2017. Lancet Public Health. 2019;4(3):e159-67. https://doi.org/10.1016/S2468-2 667(19)30019-2.

2. Partridge $L$, Deelen J, Slagboom PE. Facing up to the global challenges of ageing. Nature. 2018;561(7721):45-56. https://doi.org/10.1038/s41586-018-04 57-8.

3. The People's Republic of China 2019 National Economic and social development statistical bulletin. China Statistics. 2020;03:8-22.

4. Zeng $Y$, George LK. Population ageing and old-age insurance in China. In: The SAGE Handbook of Social Gerontology; 2010. p. 420-9.

5. GBD 2016 DALYs and HALE Collaborators. Global, regional, and national disability-adjusted life-years (DALYs) for 333 diseases and injuries and healthy life expectancy (HALE) for 195 countries and territories, 1990-2016: a systematic analysis for the Global Burden of Disease Study 2016 [published correction appears in Lancet. 2017 Oct 28;390(10106):e38]. Lancet. 2017;390(10100):1260-1344. doi:https://doi.org/10.1016/S0140-6736(1 7) $32130-X$

6. Larson A, Bovbjerg V, Luck J. State clean indoor air Laws and smoking among adults with poor mental health. J Public Health Policy. 2016;37(4); 453-66. https://doi.org/10.1057/jphp.2016.17.

7. An R, Xiang X, Liu J, Guan C. Diet and self-rated health among oldest-old Chinese. Arch Gerontol Geriatr. 2018;76:125-32. https://doi.org/10.1016/j.a rchger.2018.02.011. 
8. An R, Liu G, Khan N, Yan H, Wang Y. Dietary habits and cognitive impairment risk among oldest-old Chinese. J Gerontol B Psychol Sci Soc Sci. 2019;74(3):474-83. https://doi.org/10.1093/geronb/gbw170.

9. Ramakrishnan R, He JR, Ponsonby AL, Woodward M, Rahimi K, Blair SN, et al. Objectively measured physical activity and all cause mortality: a systematic review and meta-analysis. Prev Med. 2021;143:106356. https://doi.org/10.101 6/j.ypmed.2020.106356.

10. Lee J. Associations between Physical Activity and Liver Cancer Risks and Mortality: A Systematic Review and Meta-Analysis. Int J Environ Res Public Health. 2020;17(23):8943. Published 2020 Dec 1. doi:https://doi.org/10.3390/ ijerph17238943

11. van der Ploeg HP, Chey T, Korda RJ, Banks E, Bauman A. Sitting time and allcause mortality risk in 222497 Australian adults. Arch Intern Med. 2012; 172(6):494-500. https://doi.org/10.1001/archinternmed.2011.2174.

12. Kobayashi T, Tani Y, Kino S, Fujiwara T, Kondo K, Kawachi I. Prospective Study of Engagement in Leisure Activities and All-Cause Mortality Among Older Japanese Adults [published online ahead of print, 2021 Feb 6]. J Epidemiol. 2021;https://doi.org/10.2188/jea.JE20200427. doi:https://doi.org/1 0.2188/jea.JE20200427

13. Martinez-Gomez D, Guallar-Castillon P, Garcia-Esquinas E, Bandinelli S, Rodríguez-Artalejo F. Physical activity and the effect of multimorbidity on all-cause mortality in older adults. Mayo Clin Proc. 2017;92(3):376-82. https://doi.org/10.1016/j.mayocp.2016.12.004

14. Cho J, Lee I, Park S, Jin Y, Kim D, Kim S, et al. Physical activity and all-cause mortality in Korean older adults. Ann Hum Biol. 2018;45(4):337-45. https:// doi.org/10.1080/03014460.2018.1478448.

15. Inoue K, Shono T, Matsumoto M. Absence of outdoor activity and mortality risk in older adults living at home. J Aging Phys Act. 2006;14(2):203-11. https://doi.org/10.1123/japa.14.2.203.

16. Jia BB, Yang ZX, Mao GX, Lyu YD, Wen XL, Xu WH, et al. Health effect of Forest bathing trip on elderly patients with chronic obstructive pulmonary disease. Biomed Environ Sci. 2016;29(3):212-8. https://doi.org/10.3967/bes2 016.026

17. Gu D, Zhu H, Brown T, Hoenig H, Zeng Y. Tourism experiences and selfrated health among older adults in China. J Aging Health. 2016;28(4):675703. https://doi.org/10.1177/0898264315609906.

18. Chang LC. The relationship between nature-based tourism and autonomic nervous system function among older adults. J Travel Med. 2014;21(3):15962. https://doi.org/10.1111/jtm.12108.

19. Hwang J, Kim JJ, Lee JS, Sahito N. How to Form Wellbeing Perception and Its Outcomes in the Context of Elderly Tourism: Moderating Role of Tour Guide Services. Int J Environ Res Public Health. 2020;17(3):1029. Published 2020 Feb 6. doi:https://doi.org/10.3390/ijerph17031029

20. Lättman K, Olsson LE, Friman M, Fujii S. Perceived Accessibility, Satisfaction with Daily Travel, and Life Satisfaction among the Elderly. Int J Environ Res Public Health. 2019;16(22):4498. Published 2019 Nov 14. doi:https://doi.org/1 0.3390/ijerph16224498

21. Friman M, Olsson LE. Daily Travel and Wellbeing among the Elderly. Int J Environ Res Public Health. 2020;17(7):2342. Published 2020 Mar 30. doi: https://doi.org/10.3390/ijerph17072342

22. Wenting Xia. On the Problems and Strategies of the Development of the Elderly Tourism Market in China. Creativity Innovation.2019;3(2).

23. Zeng Y, Feng Q, Hesketh T, Christensen K, Vaupel JW. Survival, disabilities in activities of daily living, and physical and cognitive functioning among the oldest-old in China: a cohort study. Lancet. 2017:389(10079):1619-29. https://doi.org/10.1016/S0140-6736(17)30548-2.

24. Chen $\mathrm{H}$. Assessment of the quality of the cross-sectional data collected in the 2008-2009 wave of Chinese longitudinal healthy longevity survey. In: Zeng Yi., editor. Research on elderly population, family, health and care needs/costs. Science Press; Beijing, China: 2010. pp. 350-352.

25. Yin Z, Fei Z, Qiu C, Brasher MS, Kraus VB, Zhao W, et al. Dietary diversity and cognitive function among elderly people: a population-based study. J Nutr Health Aging. 2017;21(10):1089-94. https://doi.org/10.1007/s12603-017-09125.

26. Folstein MF, Folstein SE, McHugh PR. "mini-mental state". A practical method for grading the cognitive state of patients for the clinician. J Psychiatr Res. 1975;12(3):189-98. https://doi.org/10.1016/0022-3956(75)9002 6-6.

27. Yang L, Martikainen $P$, Silventoinen $K$, Konttinen $H$. Association of socioeconomic status and cognitive functioning change among elderly
Chinese people. Age Ageing. 2016;45(5):674-80. https://doi.org/10.1093/a geing/afw107.

28. Gao MY, Yang M, Kuang WH, Qiu PY. Factors and validity analysis of minimental state examination in Chinese elderly people. Beijing Da Xue Xue Bao. 2015;47(3):443-9.

29. Yuan JQ, Lv YB, Chen HS, Gao X, Yin ZX, Wang WT, et al. Association Between Late-Life Blood Pressure and the Incidence of Cognitive Impairment: A Community-Based Prospective Cohort Study. J Am Med Dir Assoc. 2019;20(2):177-182.e2. doi:https://doi.org/10.1016/j.jamda.2018.05.029

30. Katz S, Ford AB, Moskowitz RW, Jackson BA, Jaffe MW. Studies of illness in the aged. The index of ADL: a standardized measure of biological and psychosocial function. JAMA. 1963;185(12):914-9. https://doi.org/10.1001/ja ma.1963.03060120024016.

31. Grambsch, Patricia M.,Therneau, Terry M. (1994). Proportional hazards tests and diagnostics based on weighted residuals., 81(3), 515-526. doi:https:// doi.org/10.1093/biomet/81.3.515, 81, 3, 515, 526.

32. Yuan $Y$, Huang F, Lin F, Zhu P, Zhu P. Green space exposure on mortality and cardiovascular outcomes in older adults: a systematic review and metaanalysis of observational studies [published online ahead of print, $2020 \mathrm{Sep}$ 19]. Aging Clin Exp Res. 2020;https://doi.org/10.1007/s40520-020-01710-0. doi:https://doi.org/10.1007/s40520-020-01710-0

33. Ou SM, Chen YT, Shih CJ, Tarng DC. Impact of physical activity on the association between lipid profiles and mortality among older people. Sci Rep. 2017;7(1):8399. Published 2017 Aug 21. doi:https://doi.org/10.1038/s41 598-017-07857-7

34. Ryan AS. Exercise in aging: its important role in mortality, obesity and insulin resistance. Aging Health. 2010;6(5):551-63. https://doi.org/10.2217/a he.10.46.

35. Aguirre LE, Villareal DT. Physical exercise as therapy for frailty. Nestle Nutr Inst Workshop Ser. 2015;83:83-92. https://doi.org/10.1159/000382065.

36. Rowiński R, Morgulec-Adamowicz N, Ogonowska-Slodownik A, Dąbrowski A, Geigle PR. Participation in leisure activities and tourism among older people with and without disabilities in Poland. Arch Gerontol Geriatr. 2017:73:82-8. https://doi.org/10.1016/j.archger.2017.07.025

\section{Publisher's Note}

Springer Nature remains neutral with regard to jurisdictional claims in published maps and institutional affiliations.
Ready to submit your research? Choose BMC and benefit from:

- fast, convenient online submission

- thorough peer review by experienced researchers in your field

- rapid publication on acceptance

- support for research data, including large and complex data types

- gold Open Access which fosters wider collaboration and increased citations

- maximum visibility for your research: over $100 \mathrm{M}$ website views per year

At $\mathrm{BMC}$, research is always in progress.

Learn more biomedcentral.com/submission 